Article

\title{
Effects of Single Amino Acid Substitution on the Biophysical Properties and Biological Activities of an Amphipathic $\alpha$-Helical Antibacterial Peptide Against Gram-Negative Bacteria
}

\author{
Juanjuan Tan ${ }^{1,3, \dagger}$, Jinfeng Huang ${ }^{4, \dagger}$, Yibing Huang ${ }^{1,2,3}$ and Yuxin Chen ${ }^{1,2,3, *}$
}

1 Key Laboratory for Molecular Enzymology and Engineering of the Ministry of Education, Jilin University, Changchun 130012, China

2 National Engineering Laboratory for AIDS Vaccine, Jilin University, Changchun 130012, China

3 School of Life Sciences, Jilin University, Changchun 130012, China

4 School of Life Sciences, Northeast Normal University, Changchun 130012, China

$\dagger$ These authors contributed equally to this work.

* Author to whom correspondence should be addressed; E-Mail: chen_yuxin@jlu.edu.cn; Tel.: +86-431-8515-5220; Fax: +86-431-8515-5200.

Received: 6 June 2014; in revised form: 6 July 2014 / Accepted: 16 July 2014 /

Published: 24 July 2014

\begin{abstract}
An antimicrobial peptide, known as V13K, was utilized as the framework to study the effects of charge, hydrophobicity and helicity on the biophysical properties and biological activities of $\alpha$-helical peptides. Six amino acids (Lys, Glu, Gly, Ser, Ala, and Leu) were individually used to substitute the original hydrophobic valine at the selected sixteenth location on the non-polar face of V13K. The results showed that the single amino acid substitutions changed the hydrophobicity of peptide analogs as monitored by RP-HPLC, but did not cause significant changes on peptide secondary structures both in a benign buffer and in a hydrophobic environment. The biological activities of the analogs exhibited a hydrophobicity-dependent behavior. The mechanism of peptide interaction with the outer membrane and cytoplasmic membrane of Gram-negative bacteria was investigated. We demonstrated that this single amino acid substitution method has valuable potential for the rational design of antimicrobial peptides with enhanced activities.
\end{abstract}


Keywords: antimicrobial peptide; hydrophobicity; biological activity; Gram-negative bacteria; mechanism of action

\section{Introduction}

The growing problems of antibiotic resistance threaten human health, due to the fact that there are few antibiotics against resistant bacteria in the pipeline [1-3]. Among bacteria, Gram-negative bacteria are considered as more difficult to deal with in clinical practice [1,2]. As a category of promising molecules, antimicrobial peptides (AMPs) have been widely investigated for their outstanding properties, such as rapid action, broad killing spectrum and difficulty in evoking resistance. Naturally existing AMPs are highly variable and most AMPs are short cationic peptides with 12-100 amino acids [4,5]. The mechanism of action of AMPs has been widely investigated, and two main modes have been accepted: membrane disruption and non-membrane disruption. The first one involves the electrostatic and hydrophobic interactions of peptides and phospholipid molecules of membrane and the latter manner involves the interaction of peptides with cytoplasmic anionic molecules $[4,6]$.

In the proposed mechanism of action, the bactericidal processing of cationic AMPs occurs in a stepwise manner and is generally rapid against both Gram-positive and Gram-negative bacteria [4,7]. The first step of the mechanism involves the migration of the AMPs toward the cell membrane due to electrostatic forces [8]. Both the cell wall of Gram-negative or Gram-positive bacteria and the inner cytoplasmic membrane of Gram-negative bacteria contain negatively charges and contribute to the electrostatic attraction of the cationic peptide [9]. The outer surface of the cell wall of Gram-negative bacteria is known to be composed of negatively charged lipopolysaccharides (LPSs), which make this type of bacteria the toughest to deal with in clinical practices. To reach the cytoplasmic membrane target, peptides first pass through LPS. AMPs destroy the outer membrane of Gram-negative bacteria by displacement of the divalent cations, such as $\mathrm{Mg}^{2+}$ and $\mathrm{Ca}^{2+}$, which stabilize the LPS by binding to the anionic phosphate groups, then AMPs target the inner membrane and destroy the inner membrane by making holes or channels [5]. Initially, cationic peptides contact with the negatively charged lipid head groups on the surface of the membrane, and an amphipathic conformation will be induced for most $\alpha$-helical AMPs. During this folding process, it is proposed that AMPs adopt a parallel orientation to the membrane [4]. Among the models to explain the permeabilizing process, the carpet model, barrelstave model and toroidal-pore model are widely accepted. Recently, based on the "barrel-stave" model [10] and the "carpet" model [11], Chen et al. proposed a "membrane discrimination" model for AMPs whose sole target is the biomembrane [12,13]. Prokaryotic and eukaryotic cell membranes have different structures and functions. Prokaryotic membranes have a high negative net charge and are predominantly composed of phosphatidylglycerol (PG), cardiolipin (CL), or phosphatidylserine (PS). In contrast, mammalian membranes are enriched in the zwitterionic phospholipids (neutral net charge) phosphatidylethanolamine (PE), phosphatidylcholine (PC) or sphingomyelin (SM) [9,14]. Moreover, the mammalian cell membrane contains cholesterol [15], it has been reported that cholesterol can dramatically reduce the activity of AMPs by stabilizing the lipid bilayer or by directly interacting and neutralizing AMPs [16]. 
The major barrier to the application of antimicrobial peptides as antibiotics is their toxicity or ability to lyse eukaryotic cells. This is perhaps not a surprising result if the target is indeed the cell membrane [17,18]. Hence, enhancing selectivity is crucial for the clinical application of AMPs. As the most widely distributed AMPs in nature, $\alpha$-helical antimicrobial peptides have been thoroughly investigated. In general, the antimicrobial activity and hemolytic activity in amphipathic $\alpha$-helical antimicrobial peptides are related to multiple physicochemical parameters, including peptide length, sequence, charge, helicity, hydrophobicity, amphipathicity, hydrophobic/hydrophilic angle and self-association [8]. We believe that a synthetic peptide approach to examining the effect of small incremental changes in the physicochemical parameters of cationic antimicrobial peptides will enable rapid progress in the rational design of peptide antibiotics. In this study, we systematically modulated the peptide biophysical properties of the parent peptide by single amino acid substitutions to explore the de novo approach of peptide design with better selectivity. The antibacterial mechanism of action against Gram-negative bacteria was also investigated with the change of peptide biophysical properties.

\section{Results and Discussion}

\subsection{Peptide Design and the Biophysical Properties}

The parent peptide (peptide P) (Figure 1), also known as peptide V13K, is an amphipathic AMP, which will be induced into an $\alpha$-helical secondary structure with a defined polar face and a non-polar face upon a hydrophobic environment as reported previously [12]. In the present study, we selected the sixteenth valine residue on the non-polar face as the substitution site and systematically replaced valine with six other amino acids (lysine, glutamic acid, serine, glycine, alanine, leucine) with different hydrophobicity. The amino acid sequences of the analogs are shown in Table 1.

As the central location substitutions had great effects on the properties of peptides [12,19], the amino acid substitutions at the sixteenth position should maximize the effect of single amino acid substitutions. It is noteworthy that, the $i \rightarrow i+3$ and $i \rightarrow i+4$ hydrophobic interactions were not changed upon the amino acid substitutions at this location; in contrast, the $i \rightarrow i+3$ and $i \rightarrow i+4$ charge interactions were altered by introducing Glu and Lys (Figure 1).

Single amino acid substitutions showed dramatic effects on the peptide hydrophobicity, as determined by the RP-HPLC retention times (Table 2). Among substitutions, the retention times ranged from $32.2 \mathrm{~min}$ (peptide V16K) to $40.4 \mathrm{~min}$ (peptide V16L), which reflect the pure effects of single amino acid substitutions. Thus, the retention times of peptides reflect the relative hydrophobicity of side chains. Consistent with previous studies [20], the hydrophobicity of peptide analogs was generally in the following order: Lys $<$ Gly $<$ Ser $<$ Ala $<$ Val $<$ Leu. Glu-substituted peptide was an exception, as it contains a negatively-charged side chain and this should decrease the hydrophobicity of the peptide dramatically. In fact, the hydrophobicity of peptide V16E was comparable with peptide V16S, which may be attributed to the fact that the electrostatic interactions between K13 and E16 may reinforce the peptide secondary structure and result in a higher relative hydrophobicity (Figure 1). 
Figure 1. Helical net representation of peptides analogs. The hydrophobic amino acid residues on the non-polar faces are boxed. The substituting amino acids on the non-polar face are circled. The lysine at the position 13 on the non-polar face is in octagon. The $i \rightarrow i$ +3 and $i \rightarrow i+4$ hydrophobic interactions and charge interactions are shown as black bars and hashed bars, respectively. The one-letter code is used for the amino acid residues.

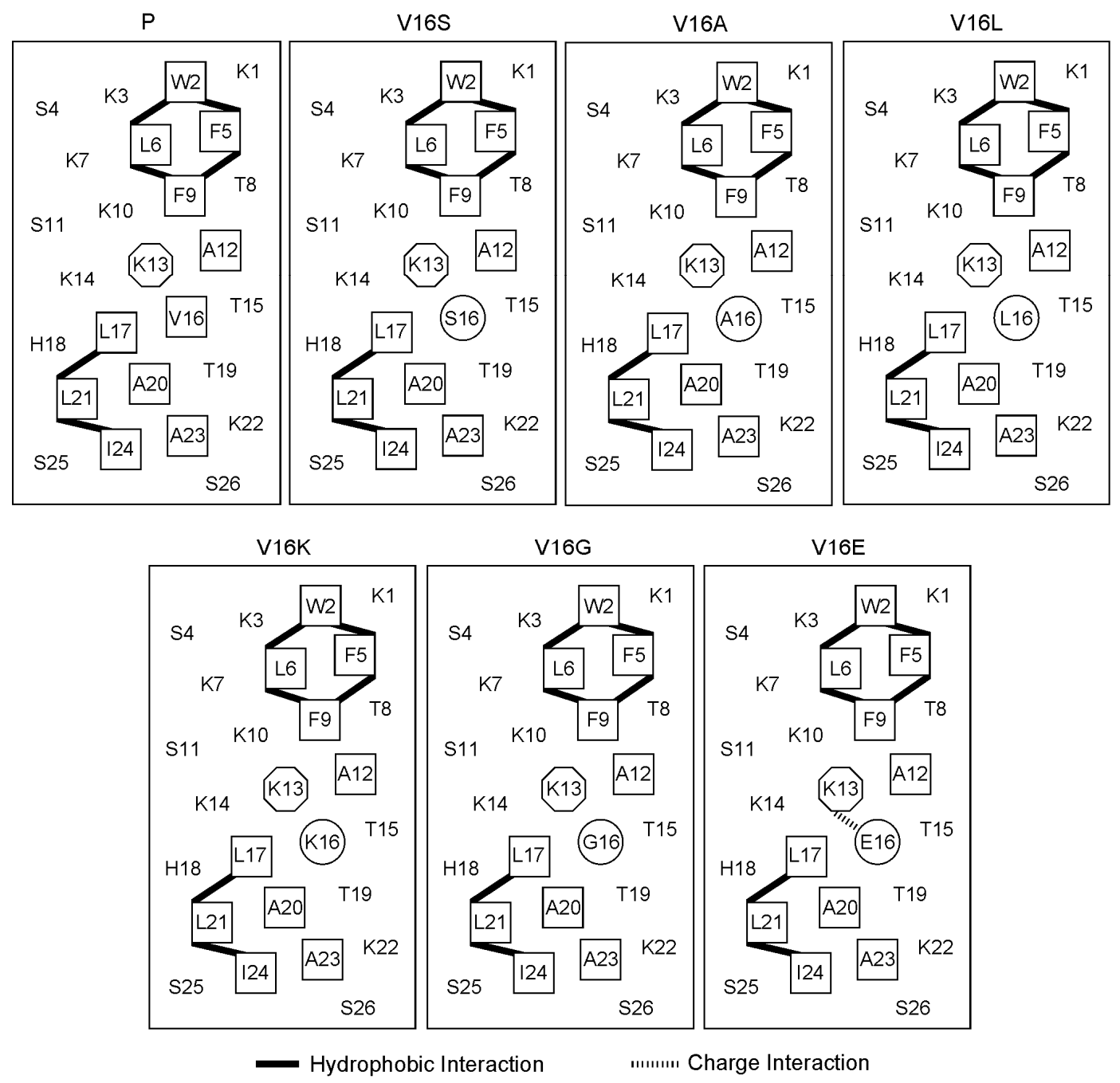

Table 1. Sequence of peptides used in this study.

\begin{tabular}{cc}
\hline Peptide & Amino Acid Sequence $^{a}$ \\
\hline P & Ac-K-W-K-S-F-L-K-T-F-K-S-A-K-K-T-V-L-H-T-A-L-K-A-I-S-S-amide \\
V16K & Ac-K-W-K-S-F-L-K-T-F-K-S-A-K-K-T- $\boldsymbol{K}$-L-H-T-A-L-K-A-I-S-S-amide \\
V16G & Ac-K-W-K-S-F-L-K-T-F-K-S-A-K-K-T- $\boldsymbol{G}$-L-H-T-A-L-K-A-I-S-S-amide \\
V16S & Ac-K-W-K-S-F-L-K-T-F-K-S-A-K-K-T-S - L-H-T-A-L-K-A-I-S-S-amide \\
V16E & Ac-K-W-K-S-F-L-K-T-F-K-S-A-K-K-T- $\boldsymbol{E}$-L-H-T-A-L-K-A-I-S-S-amide \\
V16A & Ac-K-W-K-S-F-L-K-T-F-K-S-A-K-K-T- $\boldsymbol{A}$-L-H-T-A-L-K-A-I-S-S-amide \\
V16L & Ac-K-W-K-S-F-L-K-T-F-K-S-A-K-K-T- $\boldsymbol{L}$-L-H-T-A-L-K-A-I-S-S-amide \\
\hline
\end{tabular}

${ }^{a}$ One-letter codes are used for the amino acid residues; Ac, $\mathrm{N}^{\alpha}$-acetyl; amide, $\mathrm{C}$-terminal amide; the bold and italic letters denote the substituting amino acids of the peptide P. All amino acids are L-amino acids. 
Table 2. Biophysical data of the peptide analogs.

\begin{tabular}{cccccc}
\hline \multirow{2}{*}{ Peptide $^{a}$} & \multirow{2}{*}{$\boldsymbol{t}_{\mathrm{R}}(\mathbf{m i n}){ }^{\boldsymbol{b}}$} & \multicolumn{2}{c}{ Benign $^{\boldsymbol{c}}$} & \multicolumn{2}{c}{$\mathbf{5 0 \% \text { TFE }}{ }^{\boldsymbol{d}}$} \\
\cline { 3 - 6 } & & {$[\boldsymbol{\theta}]_{\mathbf{2 2 2}}$} & $\mathbf{\% ~ h e l i x ~}^{\boldsymbol{e}}$ & {$[\boldsymbol{\theta}]_{\mathbf{2 2 2}}$} & \% helix $^{\boldsymbol{e}}$ \\
\hline V16K & 32.2 & $-1,990$ & 6.6 & $-29,313$ & 97.5 \\
V16G & 33.6 & $-2,839$ & 9.4 & $-27,857$ & 92.7 \\
V16S & 34.3 & $-1,760$ & 5.9 & $-28,949$ & 96.3 \\
V16E & 34.6 & $-3,465$ & 11.5 & $-30,063$ & 100.0 \\
V16A & 36.6 & $-3,057$ & 10.2 & $-28,769$ & 95.7 \\
P & 38.2 & $-2,592$ & 8.6 & $-29,726$ & 98.9 \\
V16L & 40.4 & $-3,595$ & 12.0 & $-29,803$ & 99.1 \\
\hline
\end{tabular}

${ }^{a}$ Peptides are ordered by relative hydrophobicity during RP-HPLC at $25{ }^{\circ} \mathrm{C} .{ }^{b}$ Retention times of peptides during RP-HPLC at $25{ }^{\circ} \mathrm{C} .{ }^{c}$ The mean residue molar ellipticities, $[\theta]_{222}\left(\right.$ degree $\left.\cdot \mathrm{cm}^{2} \cdot \mathrm{dmol}^{-1}\right)$ at wavelength $222 \mathrm{~nm}$ were measured at $25^{\circ} \mathrm{C}$ in $\mathrm{KP}$ bsuffer $\left(100 \mathrm{mM} \mathrm{KCl}, 50 \mathrm{mM} \mathrm{K} 2 \mathrm{HPO}_{4} / \mathrm{KH}_{2} \mathrm{PO}_{4}, \mathrm{pH} 7.0\right) .{ }^{d}$ The mean residue molar ellipticities, $[\theta]_{222}\left(\right.$ degree $\left.\cdot \mathrm{cm}^{2} \cdot \mathrm{dmol}^{-1}\right)$ at wavelength $222 \mathrm{~nm}$ were measured at $25{ }^{\circ} \mathrm{C}$ in $\mathrm{KP}$ buffer diluted 1:1 (v/v) with TFE. ${ }^{e}$ The helical content (in percentage) of a peptide relative to the molar ellipticity value of peptide V16E in 50\% TFE.

The secondary structures of peptides were determined in benign buffer and in a hydrophobic environment (50\% trifluoroethanol, TFE) to mimic the hydrophobic environment of the membrane. As shown in Table 2, all peptides exhibited random coil structures in the aqueous environment and were induced into a fully helical structure in the presence of 50\% TFE. According to a previous study [21], the $\alpha$-helical propensity of the seven amino acids used in this study follows the order: A $>\mathrm{L}>\mathrm{K}>\mathrm{V}>\mathrm{S}>\mathrm{E}$ $>\mathrm{G}$, which indicated that peptides V16E and V16G might exhibit smaller $\alpha$-helical content compared to other peptides. The principle of side chain interaction at the $i$ to $i+3$ and $i$ to $i+4$ positions has been used to promote $\alpha$-helix stability [22], for example, the incorporation of Lys and Glu residues to stabilize electrostatic attractions [23]. Thus, the helicity of peptide V16E in the presence of 50\% TFE that presented the greatest value among all analogs should rely on the contribution of the electrostatic attraction of the side chain of K13 and E16, which stabilizes the helix. The relative helicity is $100 \%$ for peptide V16E in 50\% TFE, showing the importance of the salt bridges of K13 and E16 to stabilize the helical structure. In general, subtle side-chain alterations by single amino acid substitutions made no significant changes on secondary structures both in aqueous and in hydrophobic environments (Table 2). The CD spectra of peptide V16G and V16E are shown in Figure 2.

\subsection{Biological Activities of Peptides Analogs}

The antimicrobial activity of the peptide analogs was determined against five Gram-negative bacterial standards and clinic strains, as shown in Table 3. The geometric mean values were used to evaluate the overall antimicrobial activity of peptides. It is clear that the antimicrobial activities of the peptides had a correlation with the peptide hydrophobicity, i.e., the more hydrophobic the peptide, the more active it is against bacteria, which is consistent with a previous study [13]. However, the introduction of the negatively-charged amino acid glutamic acid decreased the antimicrobial activity dramatically, i.e., the MIC value of V16L against $P$. aeruginosa decreased from $2 \mu \mathrm{g} / \mathrm{mL}$ to $64 \mu \mathrm{g} / \mathrm{mL}$ when a Glu-substitution was introduced (peptide V16E, Table 3). Compared with the negative-charged residue substituted analog, $\mathrm{V} 16 \mathrm{~K}$ showed much better antimicrobial activity in general against 
Gram-negative bacteria, which reinforced the importance of a net positive charge for the peptide antimicrobial activity.

Figure 2. $\mathrm{CD}$ spectra of peptide $\mathrm{V} 16 \mathrm{G}$ and $\mathrm{V} 16 \mathrm{E}$ at $\mathrm{pH} 7$ and $25{ }^{\circ} \mathrm{C}$ in $50 \mathrm{mM}$ $\mathrm{KH}_{2} \mathrm{PO}_{4} / \mathrm{K}_{2} \mathrm{HPO}_{4}$ containing $100 \mathrm{mM} \mathrm{KCl}$. Solid symbols denote the $\mathrm{CD}$ spectra of peptide analogs in KP buffer without TFE, and open symbols denote CD spectra obtained in the presence of 50\% TFE. Peptide V16G data are presented by squares and V16E by circles.

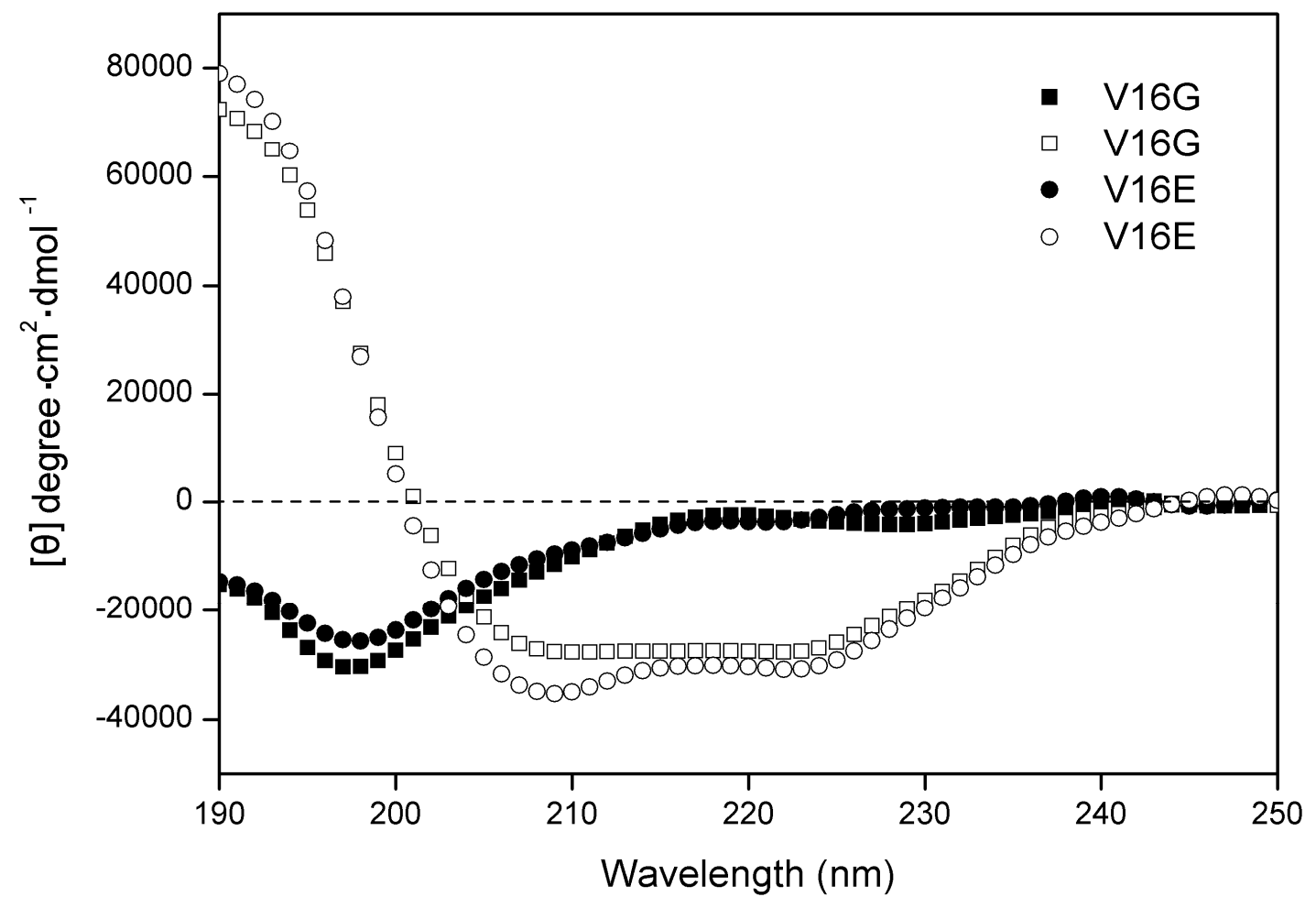

Table 3. Minimal inhibitory concentration (MIC) of peptides against Gram-negative bacteria and hemolysis percentage against human red blood cells.

\begin{tabular}{|c|c|c|c|c|c|c|c|}
\hline \multirow[b]{2}{*}{ Peptide $^{a}$} & \multicolumn{5}{|c|}{ MIC $(\mu \mathrm{g} / \mathrm{mL})$} & \multirow[b]{2}{*}{$\begin{array}{c}\text { Hemolysis } \\
\text { Percentage }^{b}\end{array}$} & \multirow[b]{2}{*}{$\mathbf{G M}^{c}$} \\
\hline & $\begin{array}{c}\text { E. coli } \\
\text { ATCC25922 }\end{array}$ & $\begin{array}{l}\text { E. coli } \\
\text { DH5 } \alpha\end{array}$ & $\begin{array}{c}E . \text { coli } \\
\text { Clinical } \\
\text { Isolate }\end{array}$ & $\begin{array}{c}\text { P. aeruginosa } \\
\text { ATCC27853 }\end{array}$ & $\begin{array}{c}\text { P. aeruginosa } \\
\mathrm{H188}\end{array}$ & & \\
\hline V16K & 32 & 16 & 8 & 32 & 16 & 6.2 & 18.4 \\
\hline V16G & 8 & 8 & 16 & 32 & 8 & 8.1 & 12.1 \\
\hline V16S & 8 & 8 & 16 & 32 & 4 & 11.3 & 10.6 \\
\hline V16E & 16 & 64 & 125 & 125 & 64 & 3.9 & 63.4 \\
\hline V16A & 2 & 4 & 1 & 4 & 4 & 14.3 & 2.6 \\
\hline $\mathrm{P}$ & 1 & 2 & 1 & 4 & 4 & 28.3 & 2.0 \\
\hline V16L & 1 & 4 & 1 & 2 & 2 & 53.9 & 1.7 \\
\hline
\end{tabular}

${ }^{a}$ Peptides are ordered by relative hydrophobicity during RP-HPLC at $25{ }^{\circ} \mathrm{C} .{ }^{b}$ Hemolysis percentage was determined at the peptide concentration of $1,000 \mu \mathrm{g} / \mathrm{mL}$ against human red blood cells. ${ }^{c}$ GM denotes the geometric mean of MIC values from all five Gram-negative bacterial strains in this table. 
The toxicity of the peptide analogs to the eukaryocyte was assessed against human red blood cells. In general, all peptide analogs exhibited little or negligible hemolytic activity. The hemolysis percentage of peptides at $1,000 \mu \mathrm{g} / \mathrm{mL}$ was plotted against the RP-HPLC retention time of the peptides (Figure 2). It is clear that the hemolytic activity of the peptides was correlated with peptide hydrophobicity as shown in Figure 3, that is, peptides with higher hydrophobicity generally exhibited stronger hemolytic activity against red blood cells.

\subsection{Outer Membrane Permeabilization and LPS Binding Affinity}

For the membrane system of Gram-negative bacteria, there is an outer membrane within the cell wall, thus, AMPs first act on the outer membrane. In this study, 1-N-phenylnaphthylamine (NPN) uptake assay was used to assess the effects of substitutions on the outer membrane permeabilization. The fluorescence character of NPN, a small hydrophobic molecule, is to show weak fluorescence in an aqueous environment but strong fluorescence in a hydrophobic environment [24]. Thus, it is widely used to detect the disruption of the outer membrane of Gram-negative bacteria $[25,26]$.

Figure 3. Relationships of peptide hydrophobicity and hemolytic activity. Hydrophobicity was expressed as the retention times of peptides in RP-HPLC at room temperature. Hemolytic activity was assessed by the percentage of peptide hemolysis at $1,000 \mu \mathrm{g} / \mathrm{mL}$.

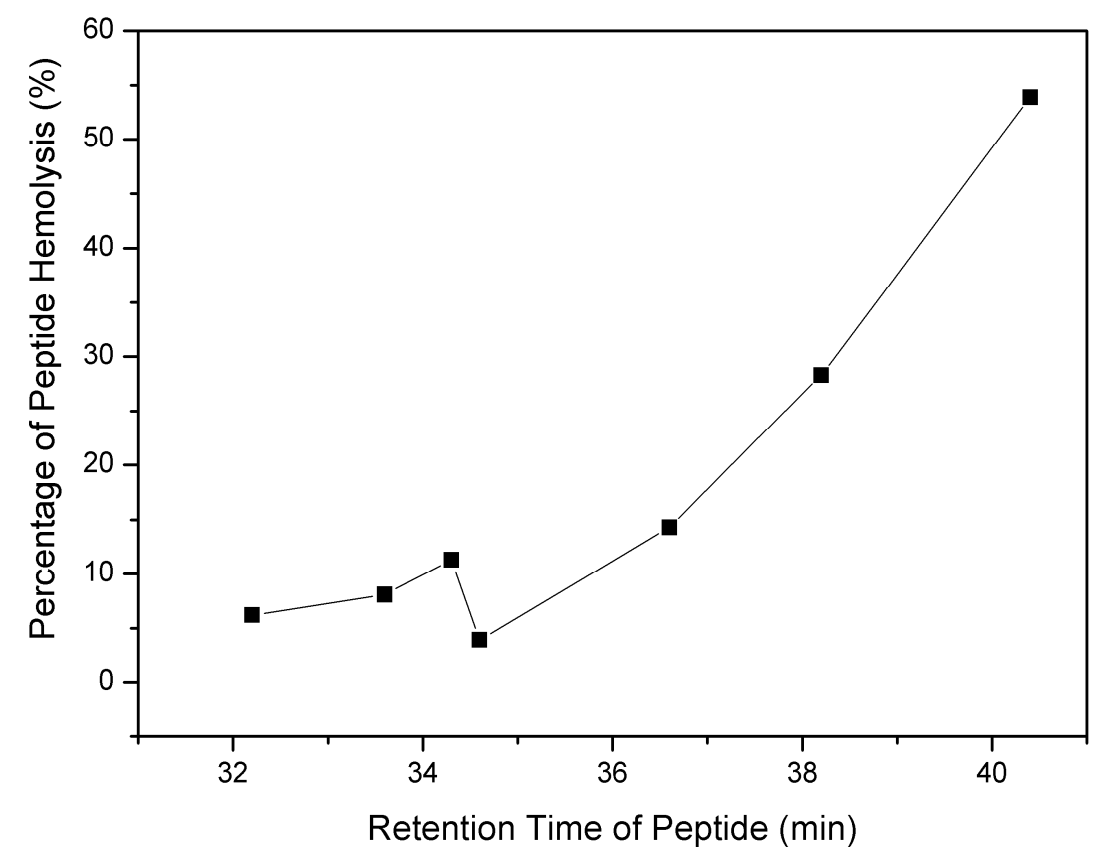

The outer membrane disturbance was reflected as an NPN fluorescence alteration as shown in Figure 4. It is worth to note that the peptide concentrations used in this assay were lower than the MIC values for most of peptides. The small incremental changes of peptide hydrophobicity caused corresponding florescence changes in the NPN uptake assay, that is, the fluorescence intensity of peptide analogs was correlated with peptide hydrophobicity, which indicated that the outer membrane of Gram-negative bacteria is "sensitive" to the peptide physiochemical parameters. Peptides with higher hydrophobicity exhibited greater outer membrane disturbance on Gram-negative bacteria (Figure 4). 
Figure 4. Outer membrane permeabilization induced by peptides as detected by NPN uptake in E. coli ATCC 25922. Neg and pos represent the negative control and positive control, respectively.

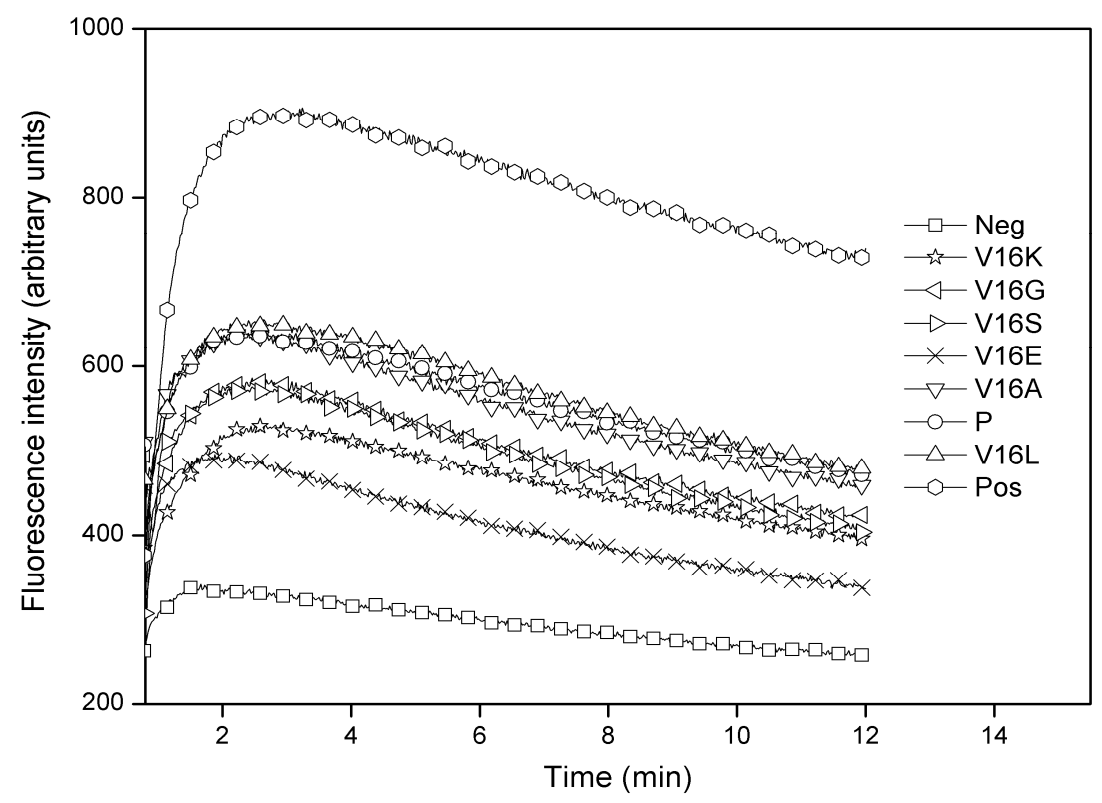

As most of the outer membrane is LPS, the affinity of peptide analogs to LPS of E. coli was further detected by dansyl-polymyxin B displacement assay [27]. As it is the polar face of the molecule that binds LPS, and all the peptides V16A, V16S, V16G and P have the same number of positively charged residues on the polar face, they would be expected to have similar effects on LPS affinity (Figure 5). However, the Lys-substituted peptide exhibited more affinity than the Ser- or Gly-substituted peptides, although V16S and V16G were more hydrophobic than V16K. This result indicates that positive charge plays an important role in the interaction of peptide with LPS.

Figure 5. Differential inhibition of dansyl-polymyxin B binding to LPS by peptide analogs.

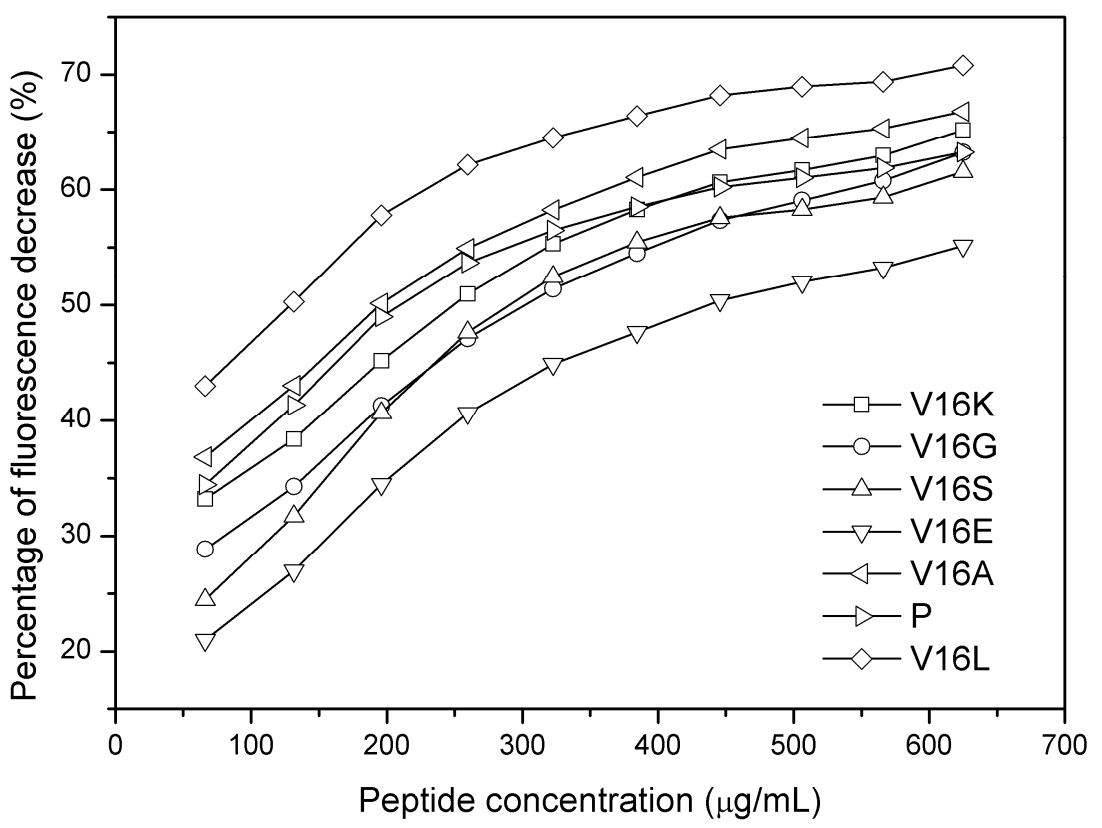




\subsection{Membrane Binding}

Upon peptide diffusion into the cytoplasmic membrane, evidence of selective interaction between peptides with bacterial versus mammalian cytoplasmic membrane was illustrated by the binding events of the peptides to anionic or zwitterionic lipid vesicles. The repositioning of the tryptophan indole group in an environment of reduced polarity upon membrane binding results in a blue shift in the fluorescence excitation maximum coupled with an enhancement of emission intensity. Lipid/peptide (L/P) ratios were maintained high enough at low peptide concentration $(2 \mu \mathrm{M})$ in order to mimic the initial steps of peptide-membrane binding [28]. The spectra were recorded as shown in Supplementary Figure S1. As shown in Table 4, the Trp emission maxima of the peptide analogs in three environments have been summarized, which were HEPES buffer only, representing an aqueous environment, buffer with PC/PG vesicles mimicking a bacterial cytoplasmic membrane, and buffer with PC/cholesterol vesicles mimicking an eukaryotic cell membrane. The significant blue shifts of $\Delta \lambda_{\max }$ (17 to $23 \mathrm{~nm}$ ) for all peptides upon exposure to $\mathrm{PC} / \mathrm{PG}$ vesicles indicated a membrane partition state of Trp in negatively charged vesicles containing 30\% anionic lipids (PG). In contrast, virtually no dramatic shifts in either maximum wavelength or fluorescence intensity were observed for all peptides with $\mathrm{PC} /$ cholesterol vesicles. Hence, the peptides in this study showed much stronger specificity against bacteria than eukaryotic cells, which was consistent with the biological activities.

Table 4. Tryptophan fluorescence emission maxima of the peptides in HEPES buffer or in the presence of PC/PG $(7: 3, \mathrm{w} / \mathrm{w})$ or PC/cholesterol $(8: 1, \mathrm{w} / \mathrm{w})$ vesicles.

\begin{tabular}{|c|c|c|c|}
\hline \multirow{2}{*}{ Peptide } & HEPES buffer & PC/PG $(7: 3, w / w)^{a}$ & PC/cholesterol $(8: 1, w / w)$ \\
\hline & \multicolumn{3}{|c|}{$\mathbf{n m}$} \\
\hline V16K & 350 & $329\left(21^{b}\right)$ & $349(1)$ \\
\hline V16G & 350 & $329(21)$ & $349(1)$ \\
\hline V16S & 350 & $328(22)$ & $349(1)$ \\
\hline V16E & 350 & $333(17)$ & $349(1)$ \\
\hline V16A & 350 & $328(22)$ & $349(1)$ \\
\hline $\mathrm{P}$ & 350 & $328(22)$ & $349(1)$ \\
\hline V16L & 350 & $326(23)$ & $348(2)$ \\
\hline
\end{tabular}

${ }^{a}$ Lipid and peptide are in a molar ratio of $50: 1 .{ }^{b}$ Blue shift in emission maximum.

It is noteworthy that the introduction of glutamic acid into the parent peptide (peptide V16E) produced the weakest blue shift $(17 \mathrm{~nm})$ upon exposure to anionic lipids, which is strongly consistent with the poorest antibacterial activity of peptide V16E. As aforementioned, the charge interaction of residue E16 with K13 may constrain the flexibility of the peptide molecule by stabilizing the $\alpha$-helical structure and decrease the net charge of the peptide. Thus, peptides with weaker positive charge and smaller non-polar faces would not insert deeply into biomembranes, as the process depends on the electrostatic interaction and hydrophobic interaction, thus resulting in the loss of antibacterial activity.

In this study, the interactions between peptides and lipids, which were illustrated by NPN assay, dansyl-polymyxin B assay and fluorescence study, are consistent with the previous studies $[18,19]$. Peptide hydrophobicity and charge play important roles in biological activities. It is also clear that subtle modulation of the sequence of antimicrobial peptides may improve the antimicrobial activity 
and specificity. The binding results of peptides with the model membranes are consistent with the "membrane discrimination" mechanism $[12,13]$.

\section{Experimental Section}

\subsection{Materials}

Rink amide 4-methylbenzhydrylamine resin $(0.8 \mathrm{mmol} / \mathrm{g})$ and all $N$ - $\alpha$-Fmoc protected amino acids were purchased from GL Biochem (Shanghai, China). The coupling reagents for peptide synthesis $O$-benzotriazole-1-yl- $N, N, N^{\prime}, N^{\prime}$-tetramethyluronium hexafluorophosphate (HBTU), 1-hydroxybenzotriazole (HOBt), $N, N^{\prime}$-diisopropylethylamine (DIEA), trifluoroacetic acid (TFA), 1- $N$-phenylnaphthylamine (NPN), polymyxin B sulfate, dansyl chloride and lipopolysaccharides (LPS) from E. coli 055:B5 were purchased from Sigma (St. Louis, MO, USA). Acetonitrile (HPLC grade) was obtained from Fisher (Hampton, NH, USA). Dichloromethane (DCM), N,N-dimethylformamide (DMF), piperidine and 2,2,2-trifluoroethanol (TFE) were analytical grade and purchased Jintai Chemicals, Changchun, China.

\subsection{Peptide Synthesis and Purification}

Peptides were synthesized on solid phase using 9-fluorenyl-methoxycarbonyl (Fmoc) chemistry as described previously [19]. Crude peptides were purified on a Shimadzu LC-6A preparative HPLC system (Shimadzu, Tokyo, Japan) using a Zorbax $300 \mathrm{SB}-\mathrm{C}_{8}$ reverse phase column $(250 \times 9.4 \mathrm{~mm}$ inner diameter, $6.5 \mu \mathrm{m}$ particle size, $300 \AA$ pore size; Agilent Technologies, Santa Clara, CA, USA) with a linear $\mathrm{AB}$ gradient at a flow rate of $2 \mathrm{~mL} / \mathrm{min}$. Mobile phase $\mathrm{A}$ was $0.1 \%$ aqueous trifluoroacetic acid (TFA) and B was $0.1 \%$ TFA in acetonitrile. The purity of the peptides was verified by analytical RP-HPLC as described below, and the purified peptides were further characterized by mass spectrometry and amino acid analysis.

\subsection{Analytical RP-HPLC of Peptides}

Peptides were analyzed on a Shimadzu LC-20A HPLC using a Zorbax $300 \mathrm{SB}_{8} \mathrm{C}_{8}$ column $(150 \times$ $4.6 \mathrm{~mm}$ i.d., $5 \mu \mathrm{m}$ particle size, $300 \AA$ pore size) from Agilent Technologies using a linear AB gradient and a flow rate of $1 \mathrm{~mL} / \mathrm{min}$, where solvents $\mathrm{A}$ and $\mathrm{B}$ were as described above. Absorbance signals of peptides were detected at $210 \mathrm{~nm}$.

\subsection{Spectroscopy}

Circular dichroism spectra were measured with a $0.02 \mathrm{~cm}$ path length quartz cuvette on a Jasco J-810 spectropolarimeter (Jasco, Tokyo, Japan) at $25{ }^{\circ} \mathrm{C}$. Data were collected from 250 to $190 \mathrm{~nm}$ at a sensitivity of 100 millidegrees, response time of $1 \mathrm{~s}$, bandwidth of $1.0 \mathrm{~nm}$ and a scan speed of $100 \mathrm{~nm} / \mathrm{min}$. Peptides were measured at a concentration of $75 \mu \mathrm{M}$ in a benign buffer $\left(50 \mathrm{mM} \mathrm{KH} \mathrm{KO}_{4} / \mathrm{K}_{2} \mathrm{HPO}_{4}\right.$, $100 \mathrm{mM} \mathrm{KCl}, \mathrm{pH} 7$ ) or the benign buffer mixed with 50\% 2,2,2-trifluoroethanol (TFE). The mean residue molar ellipticities were calculated using the equation [ $\theta]=\theta / 10 l c M n$ [29], where $\theta$ is the ellipticity in millidegrees, $l$ is the optical path length of the cuvette in centimeters, $c M$ is the peptide concentration in mole/liter and $n$ is the number of residues in the peptide. 


\subsection{Measurement of Antibacterial Activity}

Minimal inhibitory concentrations (MIC) were determined using a broth dilution method [30]. Briefly, bacteria were grown overnight at $37^{\circ} \mathrm{C}$ in Mueller-Hinton (MH) Broth, diluted in the same medium and transferred into 96-well microtiter plates $(90 \mu \mathrm{L} /$ well $)$. Peptides were serially diluted using $0.2 \%$ bovine serum albumin containing $0.01 \%$ acetic acid and added to the microtiter plates in a volume of $10 \mu \mathrm{L}$ per well to give a final concentration of $5 \times 10^{5} \mathrm{CFU} / \mathrm{mL}$. MICs were defined as the lowest peptide concentration that inhibited bacterial growth after incubation for $24 \mathrm{~h}$ at $37^{\circ} \mathrm{C}$.

\subsection{Measurement of Hemolytic Activity}

Peptide samples were serially diluted using phosphate-buffered saline (PBS) in 96-well plates (round-bottom) to give a volume of $60 \mu \mathrm{L}$ of the sample solution in each well. Human erythrocytes that had been anticoagulated using $\mathrm{EDTAK}_{2}$ were collected by centrifugation $(1,000 \times \mathrm{g})$ for $5 \mathrm{~min}$, washed twice with PBS, then diluted to a concentration of $2 \%$ in PBS. The erythrocytes ( $60 \mu \mathrm{L}$ of $2 \%$ solution) were added to each well to achieve a final concentration of $1 \%$ human erythrocytes per well, and the reactions were incubated at $37^{\circ} \mathrm{C}$ for $4 \mathrm{~h}$. The plates were then centrifuged for $10 \mathrm{~min}$ at $3000 \mathrm{rpm}$ and the supernatant $(80 \mu \mathrm{L})$ was transferred to a 96 -well plate (flat-bottom). The release of hemoglobin was determined by measuring the absorbance of the supernatant at $540 \mathrm{~nm}$. Peptide samples were diluted in a 2-fold series to determine the minimum concentration at which hemolysis occurred. Erythrocytes in PBS and distilled water were used as controls of $0 \%$ and $100 \%$ hemolysis, respectively. Hemolysis percentage was calculated by the absorbance of peptide at the concentration of $1,000 \mu \mathrm{g} / \mathrm{mL}$ and compared with the $100 \%$ hemolysis.

\subsection{Permeabilization of Bacterial Outer Membranes}

The NPN uptake assay was used to detect disturbances in the outer membrane of Gram-negative bacteria by the peptides [31]. An overnight culture of E. coli (1 mL, ATCC 25922) was transferred into $50 \mathrm{~mL}$ of $\mathrm{MH}$ broth. After incubation for $2-3 \mathrm{~h}$, middle midlog phase cells (OD600 =0.4-0.6) were washed once and resuspended to an OD600 of $0.5(5 \times 108 \mathrm{CFU} / \mathrm{mL})$ with $5 \mathrm{mM}$ HEPES buffer containing $5 \mathrm{mM} \mathrm{NaN}_{3}(\mathrm{pH}$ 7.4). Fluorescence measurements were run on a Shimadzu RF-5301 spectrofluorometer using a $3 \mathrm{~mL}$ quartz cuvette with an excitation wavelength of $350 \mathrm{~nm}$ and an emission wavelength of $420 \mathrm{~nm}$ at $25^{\circ} \mathrm{C}$. The cell suspension $(2 \mathrm{~mL})$ in the cuvette was first measured for $0.5 \mathrm{~min}$, then $20 \mu \mathrm{L}$ of NPN solution in acetone $(0.5 \mathrm{mM})$ was added and the results were recorded for about $15 \mathrm{~s}$. Immediately following this step, $20 \mu \mathrm{L}$ of peptide solution in water was added to the cuvette and the reaction cuvette was monitored for $10 \mathrm{~min}$. Assays with no peptide added or with polymyxin B sulfate (final concentration $0.64 \mu \mathrm{g} / \mathrm{mL}$ ) were used as the negative and positive controls, respectively.

\subsection{Dansyl-Polymyxin B Displacement Assay}

Dansyl-polymyxin B was synthesized, purified and quantified as reported [32]. It was then dissolved in HEPES buffer ( $5 \mathrm{mM}$, pH 7.2) at the concentration of $100 \mu \mathrm{M}$ and the final concentration of LPS is $3 \mu \mathrm{g} / \mathrm{mL}$ in the same buffer. Fluorescence measurements were run on a Shimadzu RF-5301 
spectrofluorometer using a $3 \mathrm{~mL}$ quartz cuvette with an excitation wavelength of $350 \mathrm{~nm}$ and an emission wavelength of $420 \mathrm{~nm}$ at $25{ }^{\circ} \mathrm{C}$. For displacement assay, $15 \mu \mathrm{L}$ of peptide solution $(10$ $\mathrm{mg} / \mathrm{mL}$ ) was titrated into the cuvette containing $2 \mathrm{~mL}$ LPS and $0.25 \mathrm{~mL}$ dansyl-polymyxin $\mathrm{B}$, and the decrease in the observed fluorescence (percent inhibition) was recorded.

\subsection{Preparation of Lipid Vesicles}

Unilamellar vesicles were prepared by a standard procedure with either PC/PG $(7: 3, \mathrm{w} / \mathrm{w})$ or $\mathrm{PC} /$ cholesterol $(8: 1, \mathrm{w} / \mathrm{w})$ as described previously [33]. Briefly, the desired mixtures of lipids were dissolved in a chloroform/methanol mixture $(2: 1, \mathrm{v} / \mathrm{v})$, dried under nitrogen and then lyophilized for $24 \mathrm{~h}$ to remove traces of organic solvent. Dry lipid films were suspended in $10 \mathrm{mM}$ HEPES buffer containing $150 \mathrm{mM} \mathrm{NaCl}$ ( $\mathrm{pH}$ 7.4) by vortex mixing. After five freeze-thawing cycles, the suspension was extruded 15 times through double polycarbonate membranes with $0.1 \mu \mathrm{m}$ diameter pores on an Avanti mini-extruder apparatus. The lipid concentration was determined by phosphorus analysis as previously reported [34].

\subsection{Fluorescence Spectroscopy}

Fluorescence emission spectra of peptide Trp residues were monitored by a Shimadzu RF-5301 spectrofluorometer. The excitation of wavelength was set as $280 \mathrm{~nm}$ and the emission spectra of each peptide, with or without lipid vesicles, were recorded between 300 and $450 \mathrm{~nm}$. Thus three curves were recorded for each peptide, in HEPES buffer or with either PC/PG vesicles or PC/cholesterol vesicles. The blue shift of Trp residues in vesicles were referred to in buffer condition. The final concentrations of peptide and lipid were $2 \mu \mathrm{M}$ and $100 \mu \mathrm{M}(1 / 50)$, respectively.

\section{Conclusions}

In this study, the activity of antimicrobial peptides with different hydrophobicity were investigated against Gram-negative bacteria. In general, peptide antimicrobial activity and hemolytic activity correlated with peptide hydrophobicity. Peptide membrane permeabilization was also correlated with peptide hydrophobicity. Positive charges may enhance the interactions of peptides with the bacterial outer membrane through LPS binding. The peptides in this study showed great antimicrobial activity against Gram-negative bacteria and weak hemolytic activity against human red blood cells. A single amino acid substitution approach may be valuable for the de novo design of antimicrobial peptides with enhanced activity.

\section{Supplementary Materials}

Supplementary materials can be accessed at: http://www.mdpi.com/1420-3049/19/8/10803/s1.

\section{Acknowledgments}

This work was supported by the National Natural Science Foundation of China (No. 81373445, Y. X. C.), the Innovative Team of Peptide Drugs of Jilin Province (No. 20121807, Y. X. C.), the Natural Science Foundation of Jilin Province, China (No. 20140101042JC, Y. B. H.). 


\section{Author Contributions}

J. J. T., J. F. H. and Y. X. C. designed research; J. J. T., J. F. H. and Y. B. H. performed research and analyzed the data; J. F. H. and Y. X. C. wrote the paper. All authors read and approved the final manuscript.

\section{Conflicts of Interest}

The authors declare no conflict of interest.

\section{References}

1. Kumarasamy, K.K.; Toleman, M.A.; Walsh, T.R.; Bagaria, J.; Butt, F.; Balakrishnan, R.; Chaudhary, U.; Doumith, M.; Giske, C.G.; Irfan, S. et al. Emergence of a new antibiotic resistance mechanism in India, Pakistan, and the UK: A molecular, biological, and epidemiological study. Lancet Infect. Dis. 2010, 10, 597-602.

2. Jiang, Z.; Vasil, A.I.; Gera, L.; Vasil, M.L.; Hodges, R.S. Rational design of $\alpha$-helical antimicrobial peptides to target gram-negative pathogens, acinetobacter baumannii and pseudomonas aeruginosa: Utilization of charge, "specificity determinants," total hydrophobicity, hydrophobe type and location as design parameters to improve the therapeutic ratio. Chem. Biol. Drug Des. 2011, 77, 225-240.

3. Oyston, P.C.; Fox, M.A.; Richards, S.J.; Clark, G.C. Novel peptide therapeutics for treatment of infections. J. Med. Microbiol. 2009, 58, 977-987.

4. Jenssen, H.; Hamill, P.; Hancock, R.E. Peptide antimicrobial agents. Clin. Microbiol. Rev. 2006, $19,491-511$.

5. Hancock, R.E. Peptide antibiotics. Lancet 1997, 349, 418-422.

6. Powers, J.P.; Hancock, R.E. The relationship between peptide structure and antibacterial activity. Peptides 2003, 24, 1681-1691.

7. Huang, H.W. Action of antimicrobial peptides: Two-state model. Biochemistry 2000, 39, 8347-8352.

8. Huang, Y.; Huang, J.; Chen, Y. $\alpha$-Helical cationic antimicrobial peptides: Relationships of structure and function. Protein Cell 2010, 1, 143-152.

9. Yeaman, M.R.; Yount, N.Y. Mechanisms of antimicrobial peptide action and resistance. Pharmacol. Rev. 2003, 55, 27-55.

10. Ehrenstein, G.; Lecar, H. Electrically gated ionic channels in lipid bilayers. Quar. Rev. Biophys. 1977, 10, 1-34.

11. Shai, Y. Mechanism of the binding, insertion and destabilization of phospholipid bilayer membranes by $\alpha$-helical antimicrobial and cell non-selective membrane-lytic peptides. Biochim. Biophys. Acta 1999, 1462, 55-70.

12. Chen, Y.; Mant, C.T.; Farmer, S.W.; Hancock, R.E.; Vasil, M.L.; Hodges, R.S. Rational design of $\alpha$-helical antimicrobial peptides with enhanced activities and specificity/therapeutic index. J. Biol. Chem. 2005, 280, 12316-12329. 
13. Chen, Y.; Guarnieri, M.T.; Vasil, A.I.; Vasil, M.L.; Mant, C.T.; Hodges, R.S. Role of peptide hydrophobicity in the mechanism of action of $\alpha$-helical antimicrobial peptides. Antimicrob. Agents Chemother. 2007, 51, 1398-1406.

14. Giuliani, A.; Pirri, G.; Nicoletto, S.F. Antimicrobial peptides: An overview of a promising class of therapeutics. Cent. Eur. J. Biol. 2007, 2, 1-33.

15. Tytler, E.M.; Anantharamaiah, G.M.; Walker, D.E.; Mishra, V.K.; Palgunachari, M.N.; Segrest, J.P. Molecular basis for prokaryotic specificity of magainin-induced lysis. Biochemistry 1995, 34, 4393-4401.

16. Matsuzaki, K. Why and how are peptide-lipid interactions utilized for self-defense? Magainins and tachyplesins as archetypes. Biochim. Biophys. Acta 1999, 1462, 1-10.

17. Park, S.C.; Kim, M.H.; Hossain, M.A.; Shin, S.Y.; Kim, Y.; Stella, L.; Wade, J.D.; Park, Y.; Hahm, K.S. Amphipathic $\alpha$-helical peptide, HP (2-20), and its analogues derived from helicobacter pylori: Pore formation mechanism in various lipid compositions. Biochim. Biophys. Acta 2008, 1778, 229-241.

18. Ahmad, A.; Yadav, S.P.; Asthana, N.; Mitra, K.; Srivastava, S.P.; Ghosh, J.K. Utilization of an amphipathic leucine zipper sequence to design antibacterial peptides with simultaneous modulation of toxic activity against human red blood cells. J. Biol. Chem. 2006, 281, 22029-22038.

19. Huang, J.-F.; Xu, Y.-M.; Hao, D.-M.; Huang, Y.-B.; Liu, Y.; Chen, Y. Structure-guided de novo design of $\alpha$-helical antimicrobial peptide with enhanced specificity. Pure Appl. Chem. 2010, 82, 243-257.

20. Kovacs, J.M.; Mant, C.T.; Hodges, R.S. Determination of intrinsic hydrophilicity/hydrophobicity of amino acid side chains in peptides in the absence of nearest-neighbor or conformational effects. Biopolymers 2006, 84, 283-297.

21. Zhou, N.E.; Monera, D.M.; Kay, C.M.; Hodges, R.S. $\alpha$-Helical propensity of amino acids in the hydrophobic face of an amphipathic $\alpha$-helix. Prot. Pept. Lett. 1994, 1, 114-119.

22. Scholtz, J.M.; Qian, H.; Robbins, V.H.; Baldwin, R.L. The energetics of ion-pair and hydrogen-bonding interactions in a helical peptide. Biochemistry 1993, 32, 9668-9676.

23. Monera, O.D.; Sereda, T.J.; Zhou, N.E.; Kay, C.M.; Hodges, R.S. Relationship of sidechain hydrophobicity and $\alpha$-helical propensity on the stability of the single-stranded amphipathic $\alpha$-helix. J. Pept. Sci. 1995, 1, 319-329.

24. Hancock, R.E.; Farmer, S.W.; Li, Z.S.; Poole, K. Interaction of aminoglycosides with the outer membranes and purified lipopolysaccharide and ompf porin of escherichia coli. Antimicrob. Agents Chemother. 1991, 35, 1309-1314.

25. Dewan, P.C.; Anantharaman, A.; Chauhan, V.S.; Sahal, D. Antimicrobial action of prototypic amphipathic cationic decapeptides and their branched dimers. Biochemistry 2009, 48, 5642-5657.

26. Nishida, M.; Imura, Y.; Yamamoto, M.; Kobayashi, S.; Yano, Y.; Matsuzaki, K. Interaction of a magainin-pgla hybrid peptide with membranes: Insight into the mechanism of synergism. Biochemistry 2007, 46, 14284-14290.

27. Moore, R.A.; Bates, N.C.; Hancock, R.E. Interaction of polycationic antibiotics with pseudomonas aeruginosa lipopolysaccharide and lipid a studied by using dansyl-polymyxin. Antimicrob. Agents Chemother. 1986, 29, 496-500 
28. Glukhov, E.; Stark, M.; Burrows, L.L.; Deber, C.M. Basis for selectivity of cationic antimicrobial peptides for bacterial versus mammalian membranes. J. Biol. Chem. 2005, 280, 33960-33967.

29. Lee, D.L.; Mant, C.T.; Hodges, R.S. A novel method to measure self-association of small amphipathic molecules: Temperature profiling in reversed-phase chromatography. J. Biol. Chem. 2003, 278, 22918-22927.

30. Stark, M.; Liu, L.P.; Deber, C.M. Cationic hydrophobic peptides with antimicrobial activity. Antimicrob. Agents Chemother. 2002, 46, 3585-3590.

31. Sedgwick, E.G.; Bragg, P.D. Distinct phases of the fluorescence response of the lipophilic probe n-phenyl-1-naphthylamine in intact cells and membrane vesicles of escherichia coli. Biochim. Biophys. Acta 1987, 894, 499-506.

32. Schindler, P.R.G.; Teuber, M. Action of polymyxin b on bacterial membranes: Morphological changes in the cytoplasm and in the outer membrane of Salmonella typhimurium and Escherichia coli b. Antimicrob. Agents Chemother. 1975, 8, 94-104.

33. Zhang, L.; Rozek, A.; Hancock, R.E. Interaction of cationic antimicrobial peptides with model membranes. J. Biol. Chem. 2001, 276, 35714-35722.

34. Bartlett, G.R. Phosphorus assay in column chromatography. J. Biol. Chem. 1959, 234, 466-468.

Sample Availability: Samples of the compounds are not available from the authors.

(C) 2014 by the authors; licensee MDPI, Basel, Switzerland. This article is an open access article distributed under the terms and conditions of the Creative Commons Attribution license (http://creativecommons.org/licenses/by/3.0/). 